\title{
A DEA Analysis Using Quality And Advertising As Determinants Of Strategic Group Membership In The Automobile Industry
}

\author{
Eric C. Jackson, Penn State - Erie, The Behrend College, USA
}

\begin{abstract}
This manuscript considers sales within an automotive strategic group. Sales within the "Family Car" segment are examined. The efficient uses of inputs relative to the sales generated as determined by Data Envelopment Analysis are compared. The relative efficiencies are used to identify strategic groups within the market segment and to suggest how resources may be utilized more efficiently. Data Envelopment Analysis, (DEA), is used to compare three inputs and one output for several automobile manufacturers competing for sales in the same market segment. The three inputs used are two aggregate measures of quality and one measure of the dollar volume spent on advertising by the firms. The output measure used is the volume of sales each year over a five-year period. A Kruskal and Wallis rank test is performed to confirm that the data is comparable over the five year time period. Specifically, comparisons are made to establish that no significant changes in quality or advertising expenditures have occurred during the study period. Once it has been established that no significant changes occurred during the study period for the input and output measures for the individual automotive models. Next, firms are compared using the DEA efficiencies and are grouped according to these efficiencies. The efficiency measurements indicate that there are two distinct clusters of companies formed within the market segment. The most efficient cluster is composed of five firms. The least efficient cluster is composed of five firms. An intermediate cluster of two firms exists that is neither extremely efficient nor extremely inefficient in it's utilization of resources but may be more closely aligned with the efficient firms than with the inefficient group. This stratification into groups within the market segment by efficiency suggests that practitioners might be able to adjust their utilization of resources to compete in a different strategic group. It also suggests that success within a strategic group may be impacted by how firms utilize strategic levers within their control.
\end{abstract}

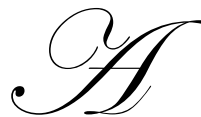

ny competitive strategy as it is applied in the business arena is measured by its success against the competition. Naturally, the ultimate measurement in the business world is in a strategy's ability to generate revenue and profits. However, it may be possible to generate profits without having the firm execute its strategy in the most efficient manner possible. Many macro factors that might impact profitability are beyond the control of the firms. It has been suggested that membership in a strategic group protected by mobility barriers (Hunt 1972; Porter 1976; Caves and Porter 1977; Porter 1979) is one such factor. The profitability of firms belonging to particular strategic groups is presumed to depend on the difficulty presented by entrance into the group and tacit collaboration by members within the strategic group (Porter 1976; Caves and Porter 1977; Porter 1979). If this is the case, then the only strategic lever under the control of a firm in a strategic group is tacit cooperation with the other members of the group. 
The argument that firms within a strategic group have a lower level of competition within their respective strategic group (Porter 1976; Caves and Porter 1977; Porter 1979; Peteraf 1993) is based to a large extent on the similarity of resources controlled by the firms in the group and that this uniformity in resources results in similar responses to perturbations in the environment. In contrast, it has also been argued that this homogeneity of resources results in an increase in rivalry within strategic groups (Hatten and Hatten 1987; Barney 1991). Empirical support for competition within strategic groups was found by Smith et el., (1997). They found that membership in a group was a predictor of the manner in which a group member responded to aggressive action by other group members. These researchers also found that firms competed both within and outside of their strategic groups, thus blurring the lines of distinction. They did not study how efficiently the firms within identified strategic groups utilized their resources. This paper considers the efficient utilization of resources as they are applied to product quality and advertising expenditures as a method of determining membership in strategic group.

The choice of product quality and advertising expenditures as determinants of strategic group membership offers insights not previously considered. Both factors are totally under the firms' control. This is in contrast to environmental factors that are not within the scope of a firm's control, such as mobility barriers preventing the entrance of a new competitor into a market segment. The analysis of factors under a firm's control allows for an analysis of the firm's performance based on its actions rather then its reactions. For example, if a firm whose use of resources is efficient is grouped with inefficient firms its performance will appear artificially high. Conversely, an inefficient firm, if grouped with efficient firms will appear to have an excessively low level of performance. This manuscript's choice of quality and advertising as factors under the control of the firm as factors for strategic group membership is based on the impact these factors have on a firm's ability to generate sales.

The use of quality as a strategic lever has been considered by Narasimhan and Mendez (2001). They examine quality as a strategic factor and find that quality must be used in conjunction with a pricing strategy. Furthermore, they demonstrated that there is a maximum price for a given threshold level of quality. If this price is exceeded, changes in quality levels will lose their effectiveness as a strategic lever. So firms competing in strategic groups should optimize their quality levels for the pricing common to their strategic group. This level of quality may be interpreted as an upper bound for membership in the group. Also acting as a limiting factor to group membership is the fact that supplying too much quality for a given market segment may lead to the cannibalization of a firm's other product lines in another market segment (Desai, (2001).

Advertising or promotion, one of the four Ps of marketing, is a means of communicating information about products to the consumer. Members in strategic groups competing in the same market segment with similar resources can control the level of advertising used to identify distinguishing the characteristics of their products. Advertising is interrelated with quality and may be combined with price as a signaling technique. This link between the price of a product as a signal of quality has been considered in the literature (Scitovsky 1945; Leavitt 1954). More recently Rao et al. (1989) showed in a meta-analysis that a positive and significant statistical relationship exists between price and perceived quality. Irandoust (1998) shows the link between pricing and quality in the Swedish automobile market. Desai (2001) examines the impact pricing has on the on a firm's demand and finds that both the pricing of its competition as well as its own pricing affects the demand for its product.

One method of determining whether or not a firm is making efficient use of its resources is to use Data Envelopment Analysis (DEA). DEA allows the researcher to establish how efficiently a firm is utilizing its inputs for a particular level of output relative to other firms in its strategic group by defining an efficient frontier. Once established this frontier can then be used to determine whether or not a firm is using its resources as efficiently as other members in the group. DEA can also be used to identify what changes might be made in the firm's use of resources so that it can move toward this efficient frontier. For example a firm that has a high and inefficient level of advertising expenditures could improve its overall efficiency by decreasing its advertising expenditures without changing its expenditures on other resources. Alternatively, a firm may find that its level of quality is higher than the other member of the strategic group and that a shift to another group within the market segment would allow its signaling via advertising and pricing to become more efficient.

This paper demonstrates that rivalry within strategic groups is actively dependent on the managerial utilization of strategic levers and it demonstrates an objective tool that may be used by practitioners to assess their 
strategic position relative to their competitors. It thereby suggests what adjustments might be made in order to make firms more efficient in the utilization of their resources. Three measures of inputs and one output are used in a DEA analysis. The measures are applied to automobile firms competing in a particular market segment and they are used to subdivide those competitors into strategic groups. Automobile firms with at least one model competing in the "Family Car" market segment are considered. Two quality factors, engineering quality and aesthetic quality, are derived from Consumers Report data collected for each automobile model.

These quality factors are chosen in light of information found in a literature review by Krishnan and Ulrich (2001) In their review of the literature of product development they note specifically that engineering design, a major factor in the establishment of the quality of a product, has not been studied in academia to the extent that it merits. The selection of engineering quality factor addresses this short-fall. Krishnan and Ulrich (2001) also note that while "aesthetic design may be one of the most important factors in explaining consumer preference...it has essentially no academic research relative to it." This observation on the importance of product aesthetics, or what is referred to in the auto industry as "Fit and Finnish", makes aesthetics a logical choice for study.

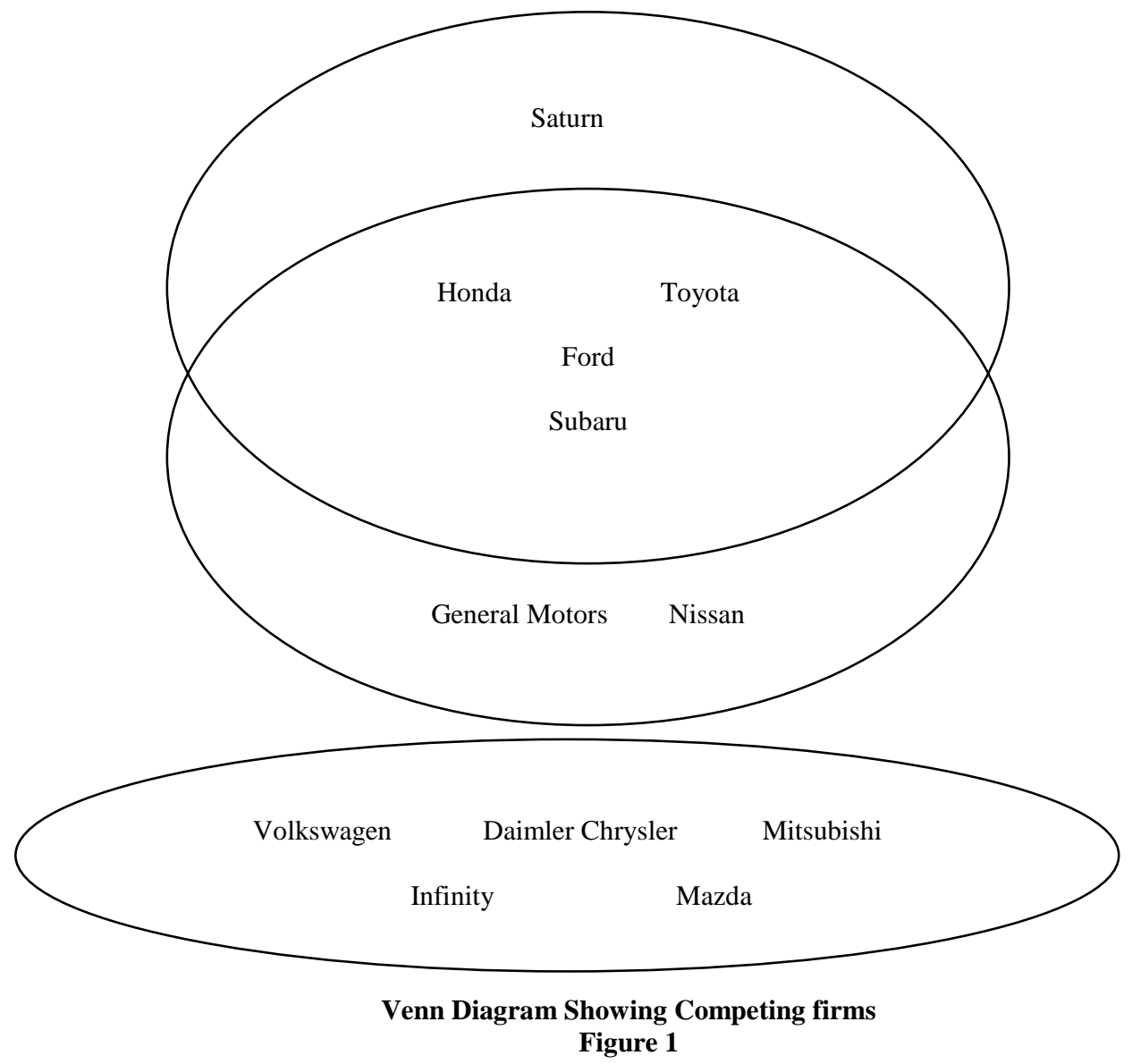

Consumer Reports data on the satisfaction of consumers relating to several attributes of automobiles is available for several years. It has the advantage of being representative of quality issues observed by the end user of automobiles. It is readily subdivided into the two quality axis of interest; one representing the aesthetic perception of auto owners, and one addressing the engineering quality or R\&D efforts of the firm. It should also be noted here that a further reason for the choice of aesthetics and engineering quality exists. Aesthetic are features that a consumer rapidly recognizes and is one that may be improved by simple manufacturing repetition. The doors fit better after the assembly line has installed several hundred of them etc. Engineering quality is one that may take several years for a consumer to appreciate. An improved power train needs time in the marketplace to demonstrate its superiority and 
gain acceptance. Thus an immediate quality factor in the form of Aesthetics (Q1), and a long term quality factor in the form of engineering improvements $(\mathrm{Q} 2)$ are considered in this research. Advertising expenditures are used as the third input factor into the DEA model. Overall the selection of these factors is consistent with Hergert's (1987) choice of factors to identify strategic groups. In particular he finds that the two most common factors across industries identifying strategic groups are $R \& D$ and advertising expenditures support the choice of these factors as inputs into this analysis.

The data for all models during a five year period of interest are examined using a Kruskal and Wallis rank test to determine if significant model changes have occurred during the time period studied. No significant changes in the two quality factors were found. Neither were significant changes in advertising expenditures for the models under consideration found. The Data Envelopment Analysis was performed and it showed that there were two separate groupings within the market segment with some stratification in the more efficient of the two groups. See Figure 1. This difference in efficiency suggests that firms within this strategic group are actively engaging in rivalry and that success may be tied back to how effectively management is utilizing its resources. See Figure 1

\section{LITERATURE OVERVIEW}

\subsection{Strategic Group}

Strategic groups have a long history in the literature. First proposed by Hunt(1972) the concept of strategic groups was addressed and refined by Porter, (1976; 1979), Caves and Porter (1977). In Porter's context, firms in strategic groups gain their competitive advantage from mobility barriers that restrict entrance to the strategic group. This restriction then allows members to benefit from tacit cooperation. Acceptance of the strategic group concept has not been universal. Barney and Hoskisson (1990) note that the concept of strategic groups needed rigorous work to prove the existence of strategic groups in general and that it remained to be demonstrated that there was indeed a connection between a firm's performance and its membership in the group. Thomas and Venkatraman (1988) noted amongst other points that the strategic group concept needed to have greater clarity in how strategic groups were defined. Hegert(1987) uses several areas suggested by Porter (1980) to develop five summary measures to describe a company's strategy these are R\&D, advertising intensity, capital intensity, business unit relationship to parent corporation and market share. Hegert (1987) found that the two measures that were the most common bases across industries are advertising and R\&D spending.

\subsection{Quality Signaling}

Price as a signal of quality has been examined extensively for many years. The argument has been made that the consumer associates a higher quality product with a higher price was reported early by Scitovsky (1945). In a later study Leavitt (1954) also found that consumers associated higher prices with higher quality. Using metaanalysis Rao et al. (1989) found a positive and significant relationship exists between price and perceived quality. Irandoust (1998) shows that a link between pricing and quality exists in the Swedish automobile market. Pricing has been linked to a firm's demand by Desai et al. (2001). They also found that the pricing of a firm's competition also affects the demand for a firm's product. Of course higher prices might reflect a greater demand or higher production costs rather than higher quality however consumers using pricing as a signal might not be unaware of these circumstances. Empirical studies have been made that counter the argument that pricing is a signal of quality and indicate that the price/quality relationship is a weak one at best (Oxenfeldt 1950; Sprokes 1977; Riesz 1978; Riesz 1979; Gerstner 1985). Gerstner (1985) suggests that one possible reason for ineffective signaling of quality by price is due to firms attempting deceive consumers. Another explanation for this lack of an effective connection is offered by Narasimhan and Mendez (2001). They found the relationship between quality and price has a limit. A maximum price for a given level of quality exists beyond which increases in quality have less impact on sales and the qualitybased strategy loses its effectiveness.

\subsection{Data Envelopment Analysis}

Data Envelopment Analysis (DEA) has been used as a methodology for determining the efficiency of decision-making units (Charners, Cooper et al. 1978; Charners, Cooper et al. 1979). Weber et al. (Weber and Desi 
1996) used DEA as a method of selecting the most efficient supplier in a JIT manufacturing environment. Narasimhan et al. (2001) used DEA as a basis for evaluating and selecting the most efficient supplier. DEA has been used to measure productivity and quality changes in hospitals(Sola et al.,(2001). Jemric et al.(2002) used DEA analysis to examine the efficiencies of Croatian banks over time. Several researchers (Sueyoshi and Aoki 2001), and (Noulas, Lazaridis et al. 2001) used DEA combined with non-parametric analysis to examine the changes of decision making units over time.

Recently DEA has been used to examine economics. Sengupta, (2002) extend the DEA approach from an operational tool used to examine efficiencies into a tool to consider economic efficiencies. He calls for the use of DEA more extensively in economic applications and actually states that, "It is hoped that this extension will bridge the gap between economists who emphasize allocative to market efficiency and the operations researches...." Cherchye (2001) uses DEA to assess macroeconomic policy performance on a national scale. As the technique of DEA gains acceptance as a tool to study economics in general, it is logical that it be used to examine the decision making policies of individual firms and to use it to make comparisons between competitive firms. Linton et al. (Linton, Walsh et al. 2002) use DEA analysis as a tool to rank and select R\&D projects that a firm should keep in its portfolio of projects. As the application of DEA to economics becomes more prevalent, it is logical that its application to strategy should be investigated.

\section{ANALYSIS}

\subsection{Data Collection}

Data for this study were collected from three sources. The annual April edition of Consumers Report (1995-2000) was used for quality information and to group models for any given year. The Ward's Automotive Yearbook (1996-2000), was used to collect information on the sales numbers for automotive models and the base price for the respective models in that model year. Lastly, the advertising rates by model for the top ten media types were collected from the Multi Media Service Ad Dollar Summary (1995-2000) for the model year.

Information was collected on twelve automotive firms, Daimler-Chrysler, Ford, General Motors, Honda, Infinity, Mazda, Mitsubishi, Nissan, Subaru, Saturn, Toyota and Volkswagen for five model years, 1995-1999. The quality, product sales numbers, advertising expenditures, and price information were collected for twenty models during the time period under consideration. Those models are specifically, Buick Century, Buick Regal, Chevrolet Lumina, Chrysler Cirrus, Dodge Stratus, Ford Contour, Ford Tarus, Honda Accord, Infiniti G20, Mazda 626, Mercury Sable, Mitsibishi Galant, Nissan Altima, Nissan Maxima, Pontiac Grand Am, Pontiac Grand Prix, Saturn Series, Subaru Legacy Toyota Camry and Volkswagen Passat. Consumer Reports groups these models as "Family Cars".

Quality reports relative to the level of problems reported by consumers are tabulated in the annual April edition of Consumer Reports. The magazine tabulates information on fourteen performance categories based on information supplied by actual automobile owners. The fourteen categories are: Engine, Cooling, Fuel, Ignition, Transmission, Electrical, Air Conditioning, Suspension, Brakes, Exhaust, Body Rust, Paint and Trim, Integrity and Hardware. The information is reported by Consumer Reports in a table using a 1-5 Likert scale. The data were collected for five model years inclusively, 1995-1999. The fourteen categories were condensed into two dimensions, one factor representing aesthetics and one representing engineering factors. The two quality axis were established by combining Engine, Cooling, Fuel, Ignition, Transmission, Electrical, Air Conditioning, Suspension, Brakes into one category, Q1, and Exhaust, Body Rust, Paint and Trim, Integrity and Hardware into the second or Q2 category. Exhaust was included in the aesthetics category since many people are sensitive to the sound of an automobile and grouping the auditory signature of an automobile into the aesthetic category incorporates this factor into the study. 
Table 1

DEA Efficiency and Ranking

\begin{tabular}{|c|c|c|c|c|c|}
\hline Model & Efficiency & Rank & Model & Efficiency & Rank \\
\hline CL_1999 & 100 & 93 & IN_1996 & 44.02 & 49 \\
\hline FT_1995 & 100 & 93 & PGP_1997 & 39.88 & 48 \\
\hline FT_1996 & 100 & 93 & MS_1996 & 39.42 & 47 \\
\hline FT_1997 & 100 & 93 & NM_1995 & 38.39 & 46 \\
\hline MS_1997 & 100 & 93 & SL_1995 & 37.96 & 45 \\
\hline NA_1999 & 100 & 93 & BC_1999 & 37.84 & 44 \\
\hline SS_1995 & 100 & 93 & MS_1995 & 36.8 & 43 \\
\hline SS_1996 & 100 & 93 & DS_1999 & 36.52 & 42 \\
\hline SS_1998 & 100 & 93 & MS_1999 & 34.87 & 41 \\
\hline FT_1999 & 95.54 & 88 & NM_1996 & 34.67 & 40 \\
\hline TC_1997 & 86.76 & 87 & MA_1995 & 33.79 & 39 \\
\hline TC_1999 & 86.71 & 86 & PGP_1998 & 33.64 & 38 \\
\hline HA_1999 & 83.1 & 85 & PGP_1996 & 32.3 & 37 \\
\hline HA_1997 & 82.83 & 84 & NA_1997 & 32.27 & 36 \\
\hline BC_1995 & 79.96 & 83 & BC_1998 & 31.89 & 35 \\
\hline TC_1998 & 79.17 & 82 & DS_1997 & 31.57 & 34 \\
\hline SL_1999 & 78.02 & 81 & MS_1998 & 31.18 & 32 \\
\hline PGA_1995 & 77.48 & 80 & DS_1998 & 31.14 & 31 \\
\hline HA_1998 & 77.28 & 79 & NA_1998 & 29.86 & 30 \\
\hline HA_1996 & 77.17 & 78 & BC_1997 & 26.66 & 29 \\
\hline SS_1999 & 77.17 & 77 & DS_1996 & 26.24 & 28 \\
\hline SS_1997 & 77.15 & 76 & MA_1996 & 25.52 & 27 \\
\hline FT_1998 & 76.36 & 75 & BR_1995 & 25.15 & 26 \\
\hline TC_1995 & 75.08 & 74 & NM_1999 & 25.07 & 25 \\
\hline HA_1995 & 72.35 & 73 & MG_1999 & 24.29 & 24 \\
\hline FC_1999 & 70.44 & 72 & DS_1995 & 23.6 & 23 \\
\hline PGA_1996 & 68.54 & 71 & MA_1997 & 23.12 & 22 \\
\hline TC_1996 & 68.1 & 70 & BR_1996 & 22.95 & 21 \\
\hline CL_1997 & 64.5 & 69 & CC_1995 & 22.58 & 20 \\
\hline SL_1997 & 64.34 & 68 & MA_1999 & 22.49 & 19 \\
\hline FC_1996 & 63.87 & 67 & MG_1997 & 20.75 & 18 \\
\hline PGA_1997 & 63.62 & 66 & BR_1998 & 19.81 & 17 \\
\hline PGA_1999 & 61.42 & 65 & VP_1996 & 18.84 & 16 \\
\hline PGP_1995 & 55.79 & 64 & BR_1999 & 18.18 & 15 \\
\hline SL_1996 & 53.31 & 63 & IN_1995 & 17.85 & 13.5 \\
\hline CL_1996 & 53.29 & 62 & MG_1995 & 17.85 & 13.5 \\
\hline NA_1995 & 52.2 & 61 & MG_1996 & 17.56 & 12 \\
\hline CL_1995 & 51.84 & 60 & BR_1997 & 16.82 & 11 \\
\hline SL_1998 & 51.4 & 59 & VP_1999 & 15.04 & 10 \\
\hline FC_1998 & 51.03 & 58 & CC_1999 & 14.99 & 9 \\
\hline FC_1997 & 50.18 & 57 & CC_1998 & 14.24 & 8 \\
\hline FC_1995 & 48.78 & 56 & VP_1995 & 13.65 & 7 \\
\hline PGA_1998 & 47.57 & 55 & CC_1997 & 12.75 & 6 \\
\hline NM_1998 & 47.32 & 54 & VP_1998 & 11.95 & 5 \\
\hline CL_1998 & 46.81 & 53 & CC_1996 & 11.41 & 4 \\
\hline NM_1997 & 46.8 & 52 & IN_1999 & 8.41 & 3 \\
\hline PGP_1999 & 46.24 & 51 & MA_1998 & 6.04 & 2 \\
\hline NA_1996 & 46.18 & 50 & VP_1997 & 5.9 & 1 \\
\hline
\end{tabular}

Advertising expenditure, as reported by the Multi Media Service Ad Dollar Summary, is available by model for the year of interest. The data are a total tabulation of the expenditures of the firm in promoting the model line in the top media types. Information on sub groups, such as the dealers' association or individual regional groups while available was not included in the advertising totals. Not including this class of data focused the study on the 
effort made by the parent firm to promote the model of interest without the complications that might have been introduced by agents not under the direct control of the parent firm itself. These sub groups, while contributing to the total advertising effort, may not have been complying with the parent firm's overreaching strategy for the model in question.

The price data used for the automotive models in question was the base price as listed in The Wards' Automotive Yearbook. In some cases this differed from the base price listed by Consumer Reports by a minor amount, a few hundred dollars out of several thousand, a difference of less than two percent in most cases. Wards' was chosen as the source of pricing since it was also the reporting agency for the advertising.

\subsection{Data Analysis, Time Periods}

Initially the information on the two quality factors, Q1 and Q2, the amount of money spent per model by the firm on advertising were used as inputs for a DEA analysis with the sales for each model used as the output. Price was not included at this stage so that any efficiencies created in sales by an inconstant pricing scheme would not bias the comparisons. Model price is used for comparison once competitive groups are defined. This DEA analysis was used to determine the relative efficiencies of the firms' utilization of resources for the measured level of sales for a given model. This was done for all models in the study for all of the various years under consideration. The radial efficiencies created using constant returns to scale were then used to establish a ranking of the models for the whole time period. See Table 1

In order to determine whether or not results from the various quality strategies that the firms of interest were following with respect to the individual models, could be compared, it was necessary to establish that a change in that policy had not occurred during the period of interest, 1995-1999. While changes in quality are generally long term strategic levers and it was not expected that a change would occur during the study period it was necessary to establish this fact with reasonable surety. In order to determine that no significant changes in model quality or advertising expenditures took place an analysis using the Kruskal-Wallis non-parametric test (Conover 1971) was performed. The efficiencies derived using Q1, Q2, and advertising for each model were ranked and the rankings were grouped by year for each of the years of interest in the study. See Table 2.

The rankings were then used to determine whether or not the information over time could be pooled. In other words, was there a significant change in quality over the years of interest. The test statistic for the KruskalWallis test is as follows and is approximately a chi-square distribution with k-1 degrees of freedom.

$$
\begin{aligned}
T & =\frac{1}{S^{2}}\left(\sum_{i=1}^{k} \frac{R_{i}^{2}}{n_{i}}-\frac{N(N+1)^{2}}{4}\right) \\
S^{2} & =\frac{1}{N-1}\left(\sum_{\text {alranks }} R\left(X_{i j}\right)^{2}-N \frac{(N+1)^{2}}{4}\right) \\
N & =\sum_{i=1}^{k} n_{i} \\
R_{i} & =\sum_{j=1}^{n_{i}} R\left(X_{i j}\right) \quad i=1,2, \ldots k
\end{aligned}
$$

The decision rule is that $\mathrm{H}_{0}$ is rejected at the $\alpha$ level if $\mathrm{T}$ exceeds the $1-\alpha$ quartile. The $\mathrm{T}$ value obtained from this calculation is 1.71 . The null hypothesis that the samples came from the same data set cannot be rejected. As a result each firms' perceived quality was determined to have remained the same over the period of interest. The analysis to compare the performance of the individual models as components of a firm was performed next. 
Table 2

DEA Efficiency and Ranking grouped by Model

\begin{tabular}{|c|c|c|c|c|c|c|c|c|c|c|c|}
\hline & & \multicolumn{2}{|l|}{1995} & \multicolumn{2}{|l|}{1996} & \multicolumn{2}{|l|}{1997} & \multicolumn{2}{|l|}{1998} & \multicolumn{2}{|l|}{1999} \\
\hline Firm & Model & Radial Efficiency & Rank & Radial Efficiency & Rank & Radial Efficiency & Rank & Radial Efficiency & Rank & Radial Efficiency & Rank \\
\hline Daimler-Chrysler & $\mathrm{CC}$ & 22.58 & 20 & 11.41 & 4 & 12.75 & 6 & 14.24 & 8 & 14.99 & 9 \\
\hline Daimler-Chrysler & DS & 23.60 & 23 & 26.24 & 28 & 31.57 & 33 & 31.14 & 31 & 36.52 & 41 \\
\hline Ford & MS & 36.80 & 42 & 39.42 & 46 & 100.00 & 92 & 31.18 & 32 & 34.87 & 40 \\
\hline Ford & FC & 48.78 & 55 & 63.87 & 66 & 50.18 & 56 & 51.03 & 57 & 70.44 & 71 \\
\hline Ford & FT & 100.00 & 92 & 100.00 & 92 & 100.00 & 92 & 76.36 & 74 & 95.54 & 87 \\
\hline General Motors & $\mathrm{BC}$ & 79.96 & 82 & & & 26.66 & 29 & 31.89 & 34 & 37.84 & 43 \\
\hline General Motors & $\mathrm{BR}$ & 25.15 & 26 & 22.95 & 21 & 16.82 & 11 & 19.81 & 17 & 18.18 & 15 \\
\hline General Motors & PGA & 77.48 & 79 & 68.54 & 70 & 63.62 & 65 & 47.57 & 54 & 61.42 & 64 \\
\hline General Motors & PGP & 55.79 & 63 & 32.30 & 36 & 39.88 & 47 & 33.64 & 37 & 46.24 & 50 \\
\hline General Motors & $\mathrm{CL}$ & 51.84 & 59 & 53.29 & 61 & 64.50 & 68 & 46.81 & 52 & 100.00 & 92 \\
\hline Honda & HA & 72.35 & 72 & 77.17 & 77 & 82.83 & 83 & 77.28 & 78 & 83.10 & 84 \\
\hline Infiniti & IN & 17.85 & 13.5 & 44.02 & 48 & & & & & 8.41 & 3 \\
\hline Mazda & MA & 33.79 & 38 & 25.52 & 27 & 23.12 & 22 & 6.04 & 2 & 22.49 & 19 \\
\hline Mitsubishi & MG & 17.85 & 13.5 & 17.56 & 12 & 20.75 & 18 & & & 24.29 & 24 \\
\hline Nissan & NA & 52.20 & 60 & 46.18 & 49 & 32.27 & 35 & 29.86 & 30 & 100.00 & 92 \\
\hline Nissan & NM & 38.39 & 45 & 34.67 & 39 & 46.80 & 51 & 47.32 & 53 & 25.07 & 25 \\
\hline Subaru & SL & 37.96 & 44 & 53.31 & 62 & 64.34 & 67 & 51.40 & 58 & 78.02 & 80 \\
\hline Saturn & SS & 100.00 & 92 & 100.00 & 92 & 77.15 & 75 & 100.00 & 92 & 77.17 & 76 \\
\hline Toyota & $\mathrm{TC}$ & 75.08 & 73 & 68.10 & 69 & 86.76 & 86 & 79.17 & 81 & 86.71 & 85 \\
\hline Volkswagen & $\mathrm{VP}$ & 13.65 & 7 & 18.84 & 16 & 5.90 & 1 & 11.95 & 5 & 15.04 & 10 \\
\hline
\end{tabular}


Table 3

DEA Efficiency and Ranking grouped by Model

\begin{tabular}{|c|c|c|c|c|c|c|c|c|c|c|c|c|c|c|c|c|c|c|c|c|c|c|c|}
\hline \multicolumn{2}{|c|}{ DC } & \multicolumn{2}{|c|}{ Ford } & \multicolumn{2}{|c|}{ GM } & \multicolumn{2}{|c|}{ Honda } & \multicolumn{2}{|c|}{ Infinity } & \multicolumn{2}{|c|}{ Mada } & \multicolumn{2}{|c|}{ Mitsubishi } & \multicolumn{2}{|c|}{ Nissan } & \multicolumn{2}{|c|}{ Subaru } & \multicolumn{2}{|c|}{ Saturn } & \multicolumn{2}{|c|}{ Toyota } & \multicolumn{2}{|c|}{ VW } \\
\hline Eff. & Rank & Eff. & Rank & Eff. & Rank & Eff. & Rank & Eff. & Rank & Eff. & Rank & Eff. & Rank & Eff. & Rank & Eff. & Rank & Eff. & Rank & Eff. & Rank & Eff. & Rank \\
\hline 22.58 & 20 & 48.78 & 55 & 79.96 & 82 & 72.35 & 72 & 17.85 & 13.5 & 33.79 & 38 & 17.85 & 13.5 & 52.2 & 60 & 37.96 & 44 & 100 & 93 & 75.08 & 73 & 13.65 & 7 \\
\hline 11.41 & 4 & 63.87 & 66 & & & 77.17 & 77 & 44.02 & 48 & 25.52 & 27 & 17.56 & 12 & 46.18 & 49 & 53.31 & 62 & 100 & 93 & 68.1 & 69 & 18.84 & 16 \\
\hline 12.75 & 6 & 50.18 & 56 & 26.66 & 29 & 82.83 & 83 & & & 23.12 & 22 & 20.75 & 18 & 32.27 & 35 & 64.34 & 67 & 77.15 & 75 & 86.76 & 86 & 5.9 & 1 \\
\hline 14.24 & 8 & 51.03 & 57 & 31.89 & 34 & 77.28 & 78 & & & 6.04 & 2 & & & 29.86 & 30 & 51.4 & 58 & 100 & 93 & 79.17 & 81 & 11.95 & 5 \\
\hline 14.99 & 9 & 70.44 & 71 & 37.84 & 43 & 83.1 & 84 & 8.41 & 3 & 22.49 & 19 & 24.29 & 24 & 100 & 93 & 78.02 & 80 & 77.17 & 76 & 86.71 & 85 & 15.04 & 10 \\
\hline 23.6 & 23 & 100 & 93 & \begin{tabular}{|l}
51.84 \\
\end{tabular} & 59 & & & & & & & & & \begin{tabular}{|l}
38.39 \\
\end{tabular} & 45 & & & & & & & & \\
\hline 26.24 & 28 & 100 & 93 & \begin{tabular}{|l}
53.29 \\
\end{tabular} & 61 & & & & & & & & & \begin{tabular}{|l|}
34.67 \\
\end{tabular} & 39 & & & & & & & & \\
\hline 31.57 & 33 & 100 & 93 & 64.5 & 68 & & & & & & & & & 46.8 & 51 & & & & & & & & \\
\hline 31.14 & 31 & 76.36 & 74 & 46.81 & 52 & & & & & & & & & \begin{tabular}{|l|l}
47.32 \\
\end{tabular} & 53 & & & & & & & & \\
\hline 36.52 & 41 & 95.54 & 87 & 100 & 93 & & & & & & & & & 25.07 & 25 & & & & & & & & \\
\hline & & 36.8 & 42 & 25.15 & 26 & & & & & & & & & & & & & & & & & & \\
\hline & & 39.42 & 46 & 22.95 & 21 & & & & & & & & & & & & & & & & & & \\
\hline & & 100 & 93 & 16.82 & 11 & & & & & & & & & & & & & & & & & & \\
\hline & & 31.18 & 32 & 19.81 & 17 & & & & & & & & & & & & & & & & & & \\
\hline & & 34.87 & 40 & 18.18 & 15 & & & & & & & & & & & & & & & & & & \\
\hline & & & & \begin{tabular}{|l}
77.48 \\
\end{tabular} & 79 & & & & & & & & & & & & & & & & & & \\
\hline & & & & 68.54 & 70 & & & & & & & & & & & & & & & & & & \\
\hline & & & & 63.62 & 65 & & & & & & & & & & & & & & & & & & \\
\hline & & & & 47.57 & 54 & & & & & & & & & & & & & & & & & & \\
\hline & & & & 61.42 & 64 & & & & & & & & & & & & & & & & & & \\
\hline & & & & 55.79 & 63 & & & & & & & & & & & & & & & & & & \\
\hline & & & & 32.3 & 36 & & & & & & & & & & & & & & & & & & \\
\hline & & & & 39.88 & 47 & & & & & & & & & & & & & & & & & & \\
\hline & & & & 33.64 & 37 & & & & & & & & & & & & & & & & & & \\
\hline & & & & 46.24 & 50 & & & & & & & & & & & & & & & & & & \\
\hline
\end{tabular}




\subsection{Data Analysis, Efficient Firms}

With no evidence to indicate that there was a statistically significant change in the efficiencies of the firms' sales output using quality levels and the level of advertising expenditure as inputs, the next question was whether or not the firms' efficiencies differed as a whole. The same type of Kruskal-Wallis analysis was performed using the entire data set as before. However, instead of pooling the data across time periods, the models were pooled relative to the firms that produced them. For example, all years for all models manufactured by General Motors were pooled into one set. All models manufactured by Daimler-Chrysler over the entire time period were pooled into another set, etc. The results are shown in Table3.

The $\mathrm{T}$ value resulting from this analysis clearly showed that there was a difference in the rankings of the firms based on their DEA efficiencies. T was equal to 61.74. In this case the null hypothesis that the samples came from the same data set can be rejected at the 0.05 level. The rejection of the null hypothesis allows for testing of the data sets, those representing the efficiency of the firms relative to their use of Q1, Q2 and advertising expenditures as inputs to generate sales as the output, to determine which pairs of the populations tend to differ. The populations $\mathrm{i}$ and $\mathrm{j}$ appear to differ if the following inequality holds true:

$$
\left|\frac{R_{i}}{n_{i}}-\frac{R_{j}}{n_{j}}\right|>t_{1-(\alpha / 2)}\left(S^{2}\left(\frac{N-1-T}{N-k}\right)^{1 / 2}\left(\frac{1}{n_{i}}+\frac{1}{n_{j}}\right)^{1 / 2}\right)
$$

where $t_{1-(\alpha / 2)}$ is the 1-( $\left.\alpha / 2\right)$ of the $t$ distribution with $\mathrm{N}-\mathrm{k}$ degrees of freedom. $\mathrm{S}$ and $\mathrm{T}$ come from the equations used in the Kruskal-Wallis test described above (Conover 1971). The results are tabulated in Table 4 and represented as a graphic in Figure 1.

Table 4

Firms Identified as having the same DEA efficiency

\begin{tabular}{|c|c|c|c|c|c|c|c|c|c|c|c|}
\hline & DC & $\mathbf{F}$ & GM & $\mathbf{H}$ & I & MAZ & MIT & NIS & SAT & SUB & TOY \\
\hline DC & - & - & - & - & - & - & - & - & - & - & - \\
\hline $\mathbf{F}$ & Different & - & - & - & - & - & - & - & - & - & - \\
\hline GM & Different & Different & - & - & - & - & - & - & - & - & - \\
\hline $\mathbf{H}$ & Different & Same & Different & - & - & - & - & - & - & - & - \\
\hline I & Same & Different & Different & Different & - & - & - & - & - & - & - \\
\hline MAZ & Same & Different & Different & Different & Same & - & - & - & - & - & - \\
\hline MIT & Same & Different & Different & Different & Same & Same & - & - & - & - & - \\
\hline NIS & Different & Different & Same & Different & Different & Different & Different & - & - & - & - \\
\hline SAT & Different & Different & Different & Same & Different & Different & Different & Different & - & - & - \\
\hline SUB & Different & Same & Same & Same & Different & Different & Different & Same & Different & - & - \\
\hline TOY & Different & Same & Different & Same & Different & Different & Different & Different & Same & Same & - \\
\hline VW & Same & Different & Different & Different & Same & Same & Same & Different & Different & Different & Different \\
\hline
\end{tabular}

Converting the information from Table 4 into the Venn diagram displayed as figure 1 above shows the groupings of firms according to the efficiency the firms demonstrate in executing their quality/advertising strategies relative to the number of units each sold.

Two distinct groups appear from this examination. Volkswagen, Mitsubishi, Daimler-Chrysler, Infinity, and Mazda compose one group of firms competing with comparable efficiencies, and Saturn, Honda, Toyota, Ford, Subaru, Nissan, and General Motors comprise a second group. Stratification exists within the second group in that while Saturn is comparable to Ford it is not comparable with General Motors but General Motors is comparable on a pair wise basis with Ford. Having identified which firms are efficient or inefficient it follows that the next logical step is to disaggregate the firms within the two categories and determine how managers may improve their position within their strategic group. 
Table 5

t-tests between inefficient group members on Q1, Q2, Sales and Advertising

Q1

\begin{tabular}{|c|c|c|c|c|c|c|}
\hline & $\mathrm{N}$ & $\begin{array}{c}\mathrm{VW} \\
5 \\
\end{array}$ & $\begin{array}{c}\text { MIT } \\
4 \\
\end{array}$ & $\begin{array}{c}\text { DC } \\
10 \\
\end{array}$ & $\begin{array}{l}\text { I } \\
3 \\
\end{array}$ & $\begin{array}{c}\text { MAZ } \\
5 \\
\end{array}$ \\
\hline VW & $\begin{array}{c}\text { Mean } \\
\text { Sig 1-tail } \\
\end{array}$ & - & $\begin{array}{c}3.7222 \\
0.31 \\
\end{array}$ & $\begin{array}{l}3.7444 \\
\\
0.355 \\
\end{array}$ & $\begin{array}{l}4.6667 \\
\mathbf{0 . 0 3 8 5} \\
\end{array}$ & $\begin{array}{l}4.0667 \\
0.3635 \\
\end{array}$ \\
\hline MIT & $\begin{array}{c}\text { Mean } \\
\text { Sig 1-tail } \\
\end{array}$ & $\begin{array}{c}3.9111 \\
0.31 \\
\end{array}$ & - & $\begin{array}{l}3.7444 \\
0.4775 \\
\end{array}$ & $\begin{array}{l}4.6667 \\
\mathbf{0 . 0 1 1} \\
\end{array}$ & $\begin{array}{r}4.0667 \\
0.196 \\
\end{array}$ \\
\hline DC & $\begin{array}{c}\text { Mean } \\
\text { Sig 1-tail }\end{array}$ & $\begin{array}{l}3.9111 \\
0.355 \\
\end{array}$ & $\begin{array}{l}3.7222 \\
0.4775 \\
\end{array}$ & - & $\begin{array}{r}4.6667 \\
\mathbf{0 . 0 1 6 5} \\
\end{array}$ & $\begin{array}{r}4.0667 \\
0.243 \\
\end{array}$ \\
\hline I & $\begin{array}{c}\text { Mean } \\
\text { Sig 1-tail } \\
\end{array}$ & $\begin{array}{l}3.9111 \\
\mathbf{0 . 0 3 8 5} \\
\end{array}$ & $\begin{array}{l}3.7222 \\
0.011 \\
\end{array}$ & $\begin{array}{l}3.7444 \\
0.0165 \\
\end{array}$ & - & $\begin{array}{l}4.0667 \\
0.0765 \\
\end{array}$ \\
\hline MAZ & $\begin{array}{c}\text { Mean } \\
\text { Sig 1-tail }\end{array}$ & $\begin{array}{l}3.9111 \\
0.3635 \\
\end{array}$ & $\begin{array}{l}3.7222 \\
0.196\end{array}$ & $\begin{array}{c}3.7444 \\
0.243\end{array}$ & $\begin{array}{l}4.6667 \\
0.0765 \\
\end{array}$ & - \\
\hline
\end{tabular}

Sales

\begin{tabular}{|c|c|c|c|c|c|c|}
\hline & $\mathrm{N}$ & $\begin{array}{c}\mathrm{VW} \\
5 \\
\end{array}$ & $\begin{array}{c}\text { MIT } \\
4 \\
\end{array}$ & $\begin{array}{l}\text { DC } \\
10 \\
\end{array}$ & $\begin{array}{l}\text { I } \\
3 \\
\end{array}$ & $\begin{array}{c}\text { MAZ } \\
5 \\
\end{array}$ \\
\hline yW & Mean & - & 15843.5 & 17066 & 23031.67 & 16288 \\
\hline & Sig 1-tail & - & 0.0005 & 0.0005 & 0.0365 & 0 \\
\hline MIT & Mean & 20615 & - & 17066 & 23031.67 & 16288 \\
\hline & Sig 1-tail & 0.0005 & - & 0.0955 & 0.001 & 0.2865 \\
\hline DC & Mean & 20615 & 15843.5 & - & 23031.67 & 16288 \\
\hline & Sig 1-tail & 0.0005 & 0.0955 & - & 0.001 & 0.18 \\
\hline I & Mean & 20615 & 15843.5 & 17066 & - & 16288 \\
\hline & Sig 1-tail & 0.0365 & 0.001 & 0.001 & - & 0.002 \\
\hline & Mean & 20615 & 15843.5 & 17066 & 23031.67 & - \\
\hline & Sig 1-tail & 0 & 0.2865 & 0.18 & 0.002 & - \\
\hline
\end{tabular}

Q2

\begin{tabular}{|c|c|c|c|c|c|c|}
\hline & $\mathrm{N}$ & $\begin{array}{c}\mathrm{VW} \\
5\end{array}$ & $\begin{array}{c}\text { MIT } \\
4\end{array}$ & $\begin{array}{l}\text { DC } \\
10\end{array}$ & $\begin{array}{l}\text { I } \\
3\end{array}$ & $\begin{array}{c}\text { MAZ } \\
5\end{array}$ \\
\hline VW & $\begin{array}{c}\text { Mean } \\
\text { Sig 1-tail }\end{array}$ & - & $\begin{array}{c}3.75 \\
0.2845\end{array}$ & $\begin{array}{c}3.92 \\
0.4505\end{array}$ & $\begin{array}{l}4.6667 \\
\mathbf{0 . 0 2 6}\end{array}$ & $\begin{array}{l}4.12 \\
0.29\end{array}$ \\
\hline MIT & $\begin{array}{c}\text { Mean } \\
\text { Sig 1-tail }\end{array}$ & $\begin{array}{r}3.96 \\
0.2845 \\
\end{array}$ & - & $\begin{array}{r}3.92 \\
0.3155 \\
\end{array}$ & $\begin{array}{l}4.6667 \\
\mathbf{0 . 0 1 7 5} \\
\end{array}$ & $\begin{array}{r}4.12 \\
0.1385 \\
\end{array}$ \\
\hline DC & $\begin{array}{c}\text { Mean } \\
\text { Sig 1-tail }\end{array}$ & $\begin{array}{c}3.96 \\
0.4505\end{array}$ & $\begin{array}{c}3.75 \\
0.3155\end{array}$ & - & $\begin{array}{l}4.6667 \\
\mathbf{0 . 0 1 3 5}\end{array}$ & $\begin{array}{c}4.12 \\
0.2285\end{array}$ \\
\hline I & $\begin{array}{c}\text { Mean } \\
\text { Sig 1-tail } \\
\end{array}$ & $\begin{array}{r}3.96 \\
\mathbf{0 . 0 2 6} \\
\end{array}$ & $\begin{array}{r}3.75 \\
\mathbf{0 . 0 1 7 5} \\
\end{array}$ & $\begin{array}{r}3.92 \\
\mathbf{0 . 0 1 3 5} \\
\end{array}$ & - & $\begin{array}{r}4.12 \\
\mathbf{0 . 0 3 4} \\
\end{array}$ \\
\hline MAZ & $\begin{array}{c}\text { Mean } \\
\text { Sig 1-tail }\end{array}$ & $\begin{array}{l}3.96 \\
0.29\end{array}$ & $\begin{array}{c}3.75 \\
0.1385\end{array}$ & $\begin{array}{c}3.92 \\
0.2285\end{array}$ & $\begin{array}{l}4.6667 \\
\mathbf{0 . 0 3 4}\end{array}$ & - \\
\hline
\end{tabular}

Advertising

\begin{tabular}{|c|c|c|c|c|c|c|}
\cline { 3 - 7 } \multicolumn{2}{c|}{} & VW & MIT & DC & I & MAZ \\
\hline \multirow{2}{c}{ VW } & Mean & - & 30860.3 & 30669.74 & 2653.6 & 26759.38 \\
& Sig 1-tail & - & 0.255 & 0.2305 & 0.065 & 0.3235 \\
\hline \multirow{2}{*}{ MIT } & Mean & 21546.88 & - & 30669.74 & 2653.6 & 26759.38 \\
& Sig 1-tail & 0.255 & - & 0.4935 & $\mathbf{0 . 0 2 4 5}$ & 0.349 \\
\hline \multirow{2}{*}{ DC } & Mean & 21546.88 & 30860.3 & - & 2653.6 & 26759.38 \\
& Sig 1-tail & 0.2305 & 0.4935 & - & $\mathbf{0 . 0 0 0 5}$ & 0.304 \\
\hline \multirow{2}{*}{ I } & Mean & 21546.88 & 30860.3 & 30669.74 & - & 26759.38 \\
& Sig 1-tail & 0.065 & $\mathbf{0 . 0 2 4 5}$ & $\mathbf{0 . 0 0 0 5}$ & & $\mathbf{0 . 0 0 1}$ \\
\hline \multirow{2}{*}{ MAZ } & Mean & 21546.88 & 30860.3 & 30669.74 & 2653.6 & - \\
& Sig 1-tail & 0.3235 & 0.349 & 0.304 & $\mathbf{0 . 0 0 1}$ & - \\
\hline
\end{tabular}


Table 6

t-tests between efficient group members on Q1, Q2, Sales and Advertising

\section{Q1}

\begin{tabular}{|c|c|c|c|c|c|c|c|c|}
\cline { 2 - 9 } \multicolumn{2}{l|}{} & GM & NIS & SUB & F & TOY & H & SAT \\
\hline \multirow{2}{*}{ GM } & Mean & - & 4.4 & 4.52 & 3.6519 & 4.6444 & 4.6889 & 4.2 \\
& Sig 1-tail & - & $\mathbf{0 . 0 0 8 5}$ & $\mathbf{0 . 0 1 4 5}$ & 0.179 & $\mathbf{0 . 0 0 0}$ & $\mathbf{0}$ & 0.1805 \\
\hline \multirow{2}{*}{ NIS } & Mean & 3.8796 & - & 4.52 & 3.6519 & 4.6444 & 4.6889 & 4.2 \\
& Sig 1-tail & $\mathbf{0 . 0 0 8 5}$ & - & 0.418 & $\mathbf{0 . 0 0 4}$ & 0.1 & 0.0675 & 0.2845 \\
\hline \multirow{2}{*}{ SUB } & Mean & 3.8796 & 4.4 & - & 3.6519 & 4.6444 & 4.6889 & 4.2 \\
& Sig 1-tail & 0.181 & 0.2845 & - & 0.0825 & 0.068 & $\mathbf{0 . 0 4 6 5}$ & 0.326 \\
\hline \multirow{2}{*}{ F } & Mean & 3.8796 & 4.4 & 4.52 & - & 4.6444 & 4.6889 & 4.2 \\
& Sig 1-tail & 0.179 & $\mathbf{0 . 0 0 4}$ & $\mathbf{0 . 0 0 6}$ & - & $\mathbf{0}$ & $\mathbf{0}$ & .0825 \\
\hline \multirow{2}{*}{ OY } & ean & .8796 & .4 & .52 & .6519 & & .6889 & .2 \\
& Sig 1-tail & $\mathbf{0 . 0 0 0}$ & 0.1 & 0.068 & $\mathbf{0}$ & - & 0.3755 & 0.068 \\
\hline \multirow{2}{*}{ H } & Mean & 3.8796 & 4.4 & 4.52 & 3.6519 & 4.6444 & - & 4.2 \\
& Sig 1-tail & $\mathbf{0}$ & 0.0675 & $\mathbf{0 . 0 4 6 5}$ & $\mathbf{0}$ & 0.3755 & - & 0.089 \\
\hline \multirow{2}{*}{ SAT } & Mean & 3.8796 & 4.4 & 4.52 & 3.6519 & 4.6444 & 4.6889 & - \\
& Sig 1-tail & $\mathbf{0 . 0 1 4 5}$ & 0.418 & 0.326 & $\mathbf{0 . 0 0 6}$ & 0.068 & 0.089 & - \\
\hline
\end{tabular}

Q2

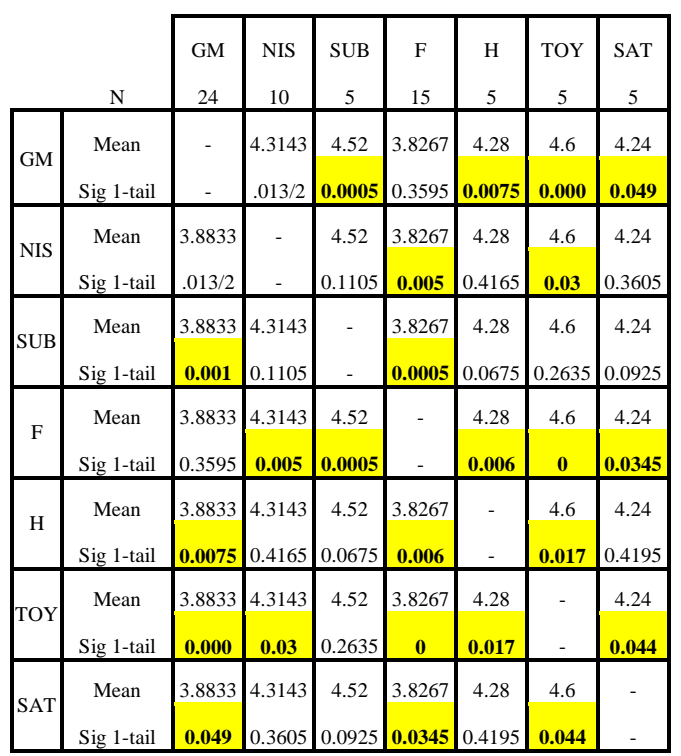

Sales

\begin{tabular}{|c|c|c|c|c|c|c|c|c|}
\cline { 2 - 10 } \multicolumn{2}{c|}{} & GM & NIS & SUB & F & H & TOY & SAT \\
\hline \multirow{2}{*}{ GM } & Mean & - & 10532.2 & 16801.6 & 17197.07 & 15453 & 17329.6 & 10949 \\
& Sig 1-tail & - & 0.357 & $\mathbf{0 . 0 3 9 5}$ & 0.116 & $\mathbf{0}$ & 0.127 & $\mathbf{0}$ \\
\hline NIS & Mean & 18107.63 & - & 16801.6 & 17197.07 & 15453 & 17329.6 & 10949 \\
& Sig 1-tail & 0.357 & - & 0.0775 & 0.138 & $\mathbf{0 . 0 0 7 5}$ & 0.153 & $\mathbf{0}$ \\
\hline \multirow{2}{*}{ SUB } & Mean & 18107.63 & 18532.2 & - & 17197.07 & 15453 & 17329.6 & 10949 \\
& Sig 1-tail & $\mathbf{0 . 0 4 0}$ & 0.0775 & - & 0.308 & $\mathbf{0 . 0 2 6}$ & 0.2275 & $\mathbf{0}$ \\
\hline \multirow{2}{*}{ F } & Mean & 18107.63 & 18532.2 & 16801.6 & - & 15453 & 17329.6 & 10949 \\
& Sig 1-tail & 0.116 & 0.138 & 0.308 & - & $\mathbf{0 . 0 0 5}$ & 0.4285 & $\mathbf{0}$ \\
\hline \multirow{2}{*}{ H } & Mean & 18107.63 & 18532.2 & 16801.6 & 17197.07 & - & 17329.6 & 10949 \\
& Sig 1-tail & $\mathbf{0}$ & $\mathbf{0 . 0 0 7 5}$ & $\mathbf{0 . 0 2 6}$ & $\mathbf{0 . 0 0 5}$ & - & $\mathbf{0 . 0 0 6 5}$ & $\mathbf{0}$ \\
\hline \multirow{2}{*}{ TOY } & Mean & 18107.63 & 18532.2 & 16801.6 & 17197.07 & 15453 & - & 10949 \\
& Sig 1-tail & 0.127 & 0.153 & 0.2275 & 0.4285 & $\mathbf{0 . 0 0 6 5}$ & - & $\mathbf{0}$ \\
\hline SAT & Mean & 18107.63 & 18532.2 & 16801.6 & 17197.07 & 15453 & 17329.6 & - \\
& Sig 1-tail & $\mathbf{0}$ & $\mathbf{0}$ & $\mathbf{0}$ & $\mathbf{0}$ & $\mathbf{0}$ & $\mathbf{0}$ & - \\
\hline
\end{tabular}

Advertising

\begin{tabular}{|c|c|c|c|c|c|c|c|c|}
\hline & $\mathrm{N}$ & $\begin{array}{c}\text { GM } \\
24 \\
\end{array}$ & $\begin{array}{c}\text { NIS } \\
10 \\
\end{array}$ & $\begin{array}{c}\text { SUB } \\
5 \\
\end{array}$ & $\begin{array}{l}\mathrm{F} \\
15 \\
\end{array}$ & $\begin{array}{l}\mathrm{H} \\
5 \\
\end{array}$ & $\begin{array}{c}\text { TOY } \\
5 \\
\end{array}$ & $\begin{array}{c}\text { SAT } \\
5 \\
\end{array}$ \\
\hline GM & $\begin{array}{c}\text { Mean } \\
\text { Sig 1-tail } \\
\end{array}$ & - & $\begin{array}{c}39850.13 \\
0.4715 \\
\end{array}$ & $\begin{array}{c}5172.84 \\
\mathbf{0} \\
\end{array}$ & \begin{tabular}{|c|}
36294.91 \\
0.3445 \\
\end{tabular} & $\begin{array}{c}95403.98 \\
.003 / 2 \\
\end{array}$ & $\begin{array}{c}79612.34 \\
0.008 \\
\end{array}$ & $\begin{array}{c}17661.18 \\
\mathbf{0} \\
\end{array}$ \\
\hline NIS & $\begin{array}{c}\text { Mean } \\
\text { Sig 1-tail }\end{array}$ & $\begin{array}{c}39131.62 \\
0.4715 \\
\end{array}$ & - & \begin{tabular}{|l|}
5172.84 \\
$\mathbf{0 . 0 0 2 5}$ \\
\end{tabular} & $\begin{array}{c}36294.91 \\
0.3765 \\
\end{array}$ & $\begin{array}{c}95403.98 \\
0.001\end{array}$ & $\begin{array}{c}79612.34 \\
0.009 \\
\end{array}$ & $\begin{array}{c}17661.18 \\
\mathbf{0 . 0 2 2 5} \\
\end{array}$ \\
\hline SUB & $\begin{array}{c}\text { Mean } \\
\text { Sig 1-tail } \\
\end{array}$ & $\begin{array}{c}39131.62 \\
\mathbf{0 . 0 0 0} \\
\end{array}$ & $\begin{array}{c}39850.13 \\
\mathbf{0 . 0 0 2 5} \\
\end{array}$ & - & $\begin{array}{c}36294.91 \\
\text { 0 } \\
\end{array}$ & $\begin{array}{c}95403.98 \\
\text { 0.0005 } \\
\end{array}$ & $\begin{array}{c}79612.34 \\
0.001 \\
\end{array}$ & $\begin{array}{c}17661.18 \\
0.007 \\
\end{array}$ \\
\hline F & $\begin{array}{c}\text { Mean } \\
\text { Sig 1-tail } \\
\end{array}$ & $\begin{array}{c}39131.62 \\
0.3445 \\
\end{array}$ & $\begin{array}{c}39850.13 \\
0.3765 \\
\end{array}$ & $\begin{array}{c}5172.84 \\
\mathbf{0} \\
\end{array}$ & - & $\begin{array}{c}95403.98 \\
\text { 0.0005 } \\
\end{array}$ & $\begin{array}{c}79612.34 \\
\mathbf{0 . 0 0 5} \\
\end{array}$ & $\begin{array}{c}17661.18 \\
0.007 \\
\end{array}$ \\
\hline $\mathrm{H}$ & \begin{tabular}{|c|} 
Mean \\
Sig 1-tail \\
\end{tabular} & $\begin{array}{c}39131.62 \\
.003 / 2 \\
\end{array}$ & $\begin{array}{c}39850.13 \\
\mathbf{0 . 0 0 1} \\
\end{array}$ & $\begin{array}{l}5172.84 \\
\mathbf{0 . 0 0 0 5} \\
\end{array}$ & $\begin{array}{c}36294.91 \\
0.0005 \\
\end{array}$ & - & \begin{tabular}{|c|}
79612.34 \\
0.1515 \\
\end{tabular} & $\begin{array}{c}17661.18 \\
\mathbf{0 . 0 0 0 5} \\
\end{array}$ \\
\hline TOY & \begin{tabular}{|c|} 
Mean \\
Sig 1-tail \\
\end{tabular} & $\begin{array}{c}39131.62 \\
\mathbf{0 . 0 0 8} \\
\end{array}$ & $\begin{array}{c}39850.13 \\
\mathbf{0 . 0 0 9} \\
\end{array}$ & \begin{tabular}{|c|}
5172.84 \\
$\mathbf{0 . 0 0 1}$ \\
\end{tabular} & $\begin{array}{c}36294.91 \\
\mathbf{0 . 0 0 5} \\
\end{array}$ & $\begin{array}{c}95403.98 \\
0.1515 \\
\end{array}$ & - & $\begin{array}{l}17661.18 \\
\mathbf{0 . 0 0 1 5} \\
\end{array}$ \\
\hline SAT & $\begin{array}{c}\text { Mean } \\
\text { Sig 1-tail }\end{array}$ & $\begin{array}{c}39131.62 \\
\text { 0 }\end{array}$ & $\begin{array}{c}39850.13 \\
\mathbf{0 . 0 2 2 5}\end{array}$ & $\begin{array}{c}5172.84 \\
0.007\end{array}$ & $\begin{array}{c}36294.91 \\
\mathbf{0 . 0 0 7}\end{array}$ & $\begin{array}{c}95403.98 \\
\mathbf{0 . 0 0 0 5}\end{array}$ & $\begin{array}{c}79612.34 \\
\mathbf{0 . 0 0 1 5}\end{array}$ & - \\
\hline
\end{tabular}




\subsection{Data Analysis Disaggregating Firms}

While determining which firms are comparable to one another in terms of their respective strategic efficiencies is interesting, of greater interest, especially to management, is where the differences between firms exist on a micro level. In other words, how firms within the same group compare with each other. This micro level information would allow corporate managers to make adjustments to compete in a different group of firms in terms of efficiency or to adjust their efficiency to more effectively compete within their own group. In order to make a comparison between firms, the inputs are pooled across models for individual firms and t-tests performed on each attribute, Q1 (engineering quality), Q2 (aesthetic quality), Advertising Expenditures, and Sales. Comparisons can then be made between group members. Table 5 shows the t-tests between the members of the inefficient group of manufacturers and Table 6 shows the same comparisons in the efficient group.

\section{DISCUSSION}

The DEA analysis in this paper divides the eleven firms being considered into two distinct groups: one group that efficiently utilizes its quality and advertising resources relative to other firms competing in the market segment and one that is not. This stratification is based on activities controlled by the firms of interest. This suggests that strategic groups may be defined based on activities totally under the control of firms. Therefore, this paper offers a method of placing firms in strategic groups and comparing their performance that is not dependant on macro environmental factors. This is beneficial in two ways.

First, it reduces the chances of misidentifying firm performance due to an inappropriate grouping. Firms that are making efficient use of their resources may be showing superior performance because of managerial activity and not simply because of tacit collusion with other members of a group protected by mobility barriers. Second, the objective comparison of resource utilization offers practitioners an opportunity to compare their strategic execution and make appropriate adjustments as needed. Management may use this method to identify either excessive or insufficient levels of advertising. They may also consider the levels of quality offered for the price as a strategic lever. A firm that has priced its products beyond the effective region of price quality interaction may make adjustments to bring the two back into alignment. Management may either shift the product line to another market segment where the price and quality levels are more compatible with other members of the strategic group or they may adjust their expenditures of resources so that the price may be lowered to bring them back into alignment with other members of the group.

\section{FUTURE RESEARCH}

Several areas of further research are foreseen using this technique. Studies examining durable goods in industries beyond the auto industry are needed. This would demonstrate that the technique can be generalized to durable goods on the whole. Once information from other industries is collected, it will be possible to consider a comparison across industries testing the robustness of the technique in a wider environment. The technique should be examined in the context of the service industry. While it is not possible to consider the longevity of the quality of an individual service, the ongoing level of quality provided by a service firm may be considered.

\section{AUTHOR INFORMATION}

Dr. Jackson received his Ph.D. from Michigan State University. His Research interests include SCM, Project Management, and Complex Dynamic Systems. He was the technical director for a multi-national specialty chemical firm for ten years and worked in the chemical field for seven years before that. He has served as managerial assistant for Decision Science Journal and as an Engineering/Business consultant for small firms in Toledo, Ohio and Detroit Michigan. He has been published in JOM and Transportation Research. 


\section{BIBLIOGRAPHY}

1. $\quad$ Barney, J. B. (1991). "Firm Resources and Sustained Competitive Advantage." Journal of Management 17: 99-120.

2. $\quad$ Barney, J. B. and R. E. Hoskisson (1990). "Strategic Groups: Untested Assertions and Research Porposals." Managerial and Decision Economics 11(3): 187-198.

3. $\quad$ Caves, R. and M. E. Porter (1977). "From Entry Barriers to Mobility Barriers." Quarterly Journal of Economics: 241-261.

4. $\quad$ Charners, A., W. W. Cooper, et al. (1978). "Measuring the Efficiency of Decisio Making Units." European Journal of Operation Research 2(6): 429-444.

5. $\quad$ Charners, A., W. W. Cooper, et al. (1979). "Measuring the Efficiency of Decision Making Units." European Journal of Operation Research 3: 339.

6. $\quad$ Cherchye, L. (2001). "Using Data Ennvelopment Analysis to Assess Macroeconomic Policy Performance." Applied Economics 33: 407-416.

7. Conover, W. J. (1971). Practical Nonparametric Statistics 2nd edition. New York, John Wiley \& Sons.

8. Desai, P. S. (2001). "Quality Segmentation in Spatial Markets: When Does Cannibalization Affect Product Line Design?" Marketing Science 20(3): 265-283.

9. $\quad$ Gerstner, E. (1985). "Do Higher Prices Signal Higher Quality?" Journal of Marketing Research 22: 215227.

10. Hatten, K. J. and M. L. Hatten (1987). "Strategic Groups, Asymmetrical Mobility Barriers and Contestability." Strategic Management Journal 8(4): 329-342.

11. Hergert, M. (1987). "Causes and Consequences of Strategic Grouping in U.S. Manufacturing Industries." International Studies of Management and Organization 1: 29-49.

12. Hunt, M. (1972). Competition in the Major Home Appliance Industry, 1960-1970, Harvard University.

13. Irandoust, M. (1998). "Pricing Policy in the Swedish Automobile Market." Jorunal of Economics and Business 50: 309-317.

14. Jemric, I. and B. Vujcic (2002). "Efficiency of Banks in Croatia: A DEA Approach." Comparative Economic Studies XLIV(2): 169-193.

15. Krishnan, V. and K. T. Ulrich (2001). "Product Development Decisions: A Review of the Literature." Management Science 47(1): 1-21.

16. Leavitt, H. J. (1954). "A Note on Some Experimental Findings About the Meaning of Price." Journal of Business 27(July): 205-210.

17. Linton, J. D., S. T. Walsh, et al. (2002). "Analysis, Ranking and Selection of R\&D Projects in a Portfolio." $R \& D$ Management 32(2): 139-148.

18. Narasimhan, R. and D. Mendez (2001). "Strategic aspects of quality: A theoretical analysis." Production and Operations Management 10(4): 514-526.

19. Narasimhan, R., S. Talluri, et al. (2001). "Supplier Evaluiation and Rationalization via Data Envelopment Analysis: An Empirical Examination." The Journal of Supply Chain Management(Summer): 28-37.

20. Noulas, A. B., J. Lazaridis, et al. (2001). "Non-Parametric Production Frontier Approach to the Study of Efficiency of Non-Life Insurance Companies in Greece." Journal of Financial Management and Analysis 14(1): 19-26.

21. Oxenfeldt, A. R. (1950). "Consumer Knowledge: Its Measurement and Extent." Review of Economics and Statistics 32: 300-314.

22. Peteraf, M. A. (1993). "Intra-industry Structure and the Response toward Rivals." Managerial and Decision Economics 14: 519-529.

23. Porter, M. E. (1976). Interbrand Choice Strategic and Bilateral Market Power. Cambrage, MA, Harvard University Press.

24. Porter, M. E. (1979). "The Structure within Industries and Companies' Performance." Review of Economics and Statistics 61(2): 214-227.

25. Porter, M. E. (1980). Competitive Strategy: Techniques for Analyzing Industries and Competitors. New York, The Free Press/Macmillan.

26. Rao, A. R. and K. B. Monroe (1989). "The Effect of Price, Brand Name and Store Name on Buyer's Preceptions of Product Quality: An Integrated Review." Journal of Marketing Research 26: 351-357.

27. Riesz, P. C. (1978). "Price Versus Quality in the Marketplace, 1961-1975." Journal of Retailing 54: 15-28. 
28. Riesz, P. C. (1979). "Price-Quality Correlations for Packaged Food Products." Journal of Consumer Affairs 13: 236-247.

29. Scitovsky, T. (1945). "Some Consequences of the Habit of Judging Quality by Price." Review of Economic Studies 12(32): 100-105.

30. Sengupta, J. K. (2002). "Economics of Efficiency Measurement by the DEA Approach." Applied Economics 34: 1133-1139.

31. Smith, K. G., C. M. CGrimm, et al. (1997). "Strategic Groups and Rivalrous Firm Behavior: Towards a Reconciliation." Strategic Management Journal 18(2): 149-157.

32. Sola, M. and D. Prior (2001). "Measuring Productivity and Quality Changes Using Data Envelopment Analysis: An Application Catalan Hospitals." Financial Accountability \& Management 17(3): 219-245.

33. Sprokes, G. B. (1977). "New Evidence on Price and Product Quality." Jorunal of Consumer Affairs 11: 6377.

34. Sueyoshi, T. and S. Aoki (2001). "A Use of a Non-Parametric Statistic for DEA Frontier Shift: The Kurskal and Wallis Rank Test." OMEGA(29): 1-18.

35. Thomas, H. and N. Venkatraman (1988). "Research on Strategic Groups: Progress and Prognosis." The Journal of Management Studies 25(6): 537-555.

36. Weber, C. A. and A. Desi (1996). "Determination of Paths to Vendor Market Efficiency Using Parallel Coordinates Representation: A negotiation Tool for Buyers." European Journal of Operation Research(90): 142-155. 


\section{NOTES}

